\title{
Clinico-Histopathological Study of Meningiomas in Correlation with Proliferative Index Ki-67
} \author{
Kartheek BVS 6 \\ ${ }^{1}$ Professor \& HOD, Dept. of Pathology, Andhra Medical College, Visakhapatnam, Andhra Pradesh, India \\ ${ }^{2}$ Professor \& HOD, Dept. of Neurosurgery, KGH/Andhra Medical College, Visakhapatnam, Andhra Pradesh, India \\ ${ }^{3}$ Post Graduate, Dept. of Pathology, Andhra Medical College, Visakhapatnam, Andhra Pradesh, India \\ ${ }^{4,5}$ Associate Professor, Dept. of Pathology, Andhra Medical College, Visakhapatnam, Andhra Pradesh, India \\ ${ }^{6}$ Assistant Professor, Dept. of Pathology, Andhra Medical College, Visakhapatnam, Andhra Pradesh, India
}

A. Bhagyalakshmi ${ }^{*}$, Satya Vara Prasad $K^{2}, K$. Venkata Swarajyalakshmi ${ }^{3}$, Parvathi $G^{4}$, Bodhireddy Sridhar Reddy ${ }^{5}$

DOI: $10.36348 /$ sjpm.2020.v05i02.008

| Received: 05.02.2020 | Accepted: 13.02.2020 | Published: 16.02.2020

*Corresponding author: Dr. A. Bhagyalakshmi

\section{Abstract}

Background: Meningiomas are the most common primary central nervous system tumours in adults. Meningiomas are slow growing tumours with a female predominance. Radiological techniques have limited ability to differentiate the subtypes of meningiomas. Grading system based on histopathological features has certain limitations in predicting the exact biological behaviour of meningiomas. Hence the use of ancillary technique is necessitatedto predict the tumour growth and recurrence. Ki67 is the most widely used immunohistochemical marker. Aim of study is to know Ki 67 proliferative index in three grades of meningiomas. Materials and methods: It is a hospital based observational study for a period of 2 years. Sample size includes 50 cases.Tissues were routinely processed and stained with hematoxylin and eosin and classified according to WHO 2016 classification. Ki 67 stains were done using poly Excel HRP/DAB Detection system. .Ki 67 labelling index: 1000 nuclei examined under 400X and results were expressed as percentage of positively stained nuclei.Interpretation of Ki 67 for Meningiomas was done based on Mukherjee et al. study. Results: Out of 50 cases most common subtype encountered is meningothelial meningioma (50\%) which is grade I tumours. Grade II and Grade III tumours accounting for 6\% and 2. \% .Mean ki67 proliferative index for grade I,grade II and grade III are $2.29 \%, 7 \%$ and $21 \%$ respectively. Conclusion: The major prognostic factors for recurrence include tumour grade, biological behaviour of tumour and extent of surgery. Ki 67 helps in predicting tumour behaviour. Therefore Ki 67 index can be used as an accessory tool to grading system and helps the surgeon in establishing better follow up criteria and long term management strategies for the benefit of the patient.

Key words: Meningiomas, ki 67 proliferative index, tumour grade.

Copyright @ 2020: This is an open-access article distributed under the terms of the Creative Commons Attribution license which permits unrestricted use, distribution, and reproduction in any medium for non-commercial use (NonCommercial, or CC-BY-NC) provided the original author and sources are credited.

\section{INTRODUCTION}

Meningiomas are the most common primary central nervous system tumours in adults. WHO classification of tumours of the Central Nervous System states that meningiomas account for $24-30 \%$ of primary intracranial neoplasms [1]. Meningiomas are slow growing tumours with a female predominance. Radiation exposure over a period of time is an important risk factor [2-4]. Neurological signs and symptoms occur mainly due to compression of adjacent structures by meningiomasHeadache and seizures herald the presence of a meningiomas.

Radiological techniques have limited ability to differentiate the subtypes of meningiomas.
Histopathological examination plays an important role in diagnosis, subtyping and grading of meningiomas

Grading system based on histopathological features has certain limitations in predicting the exact biological behaviour of meningiomas. Hence the use of ancillary technique is necessitated to predict the tumour growth and recurrence.

$\mathrm{Ki67}$ is the most widely used immunohistochemical marker that is expressed in the proliferative phase of the cell cycle [5]. It is a simple technique that can be applied on formalin-fixed paraffin - embedded sections. 


\section{Aim of study is}

To study various meningiomas in relation to age and gender

To classify meningiomas according to WHO [9] classification

To study $\mathrm{Ki} 67$ proliferative index in various meningiomas

To compare the results of $\mathrm{Ki} 67$ proliferative index with histopathological grade of meningiomas

\section{METHODS}

Study design

Hospital based observational study

\section{Study period}

2 years from October 2017 to September 2019 at Department of pathology, Andhra Medical College, Visakhapatnam

\section{Inclusion criteria}

Meningioma specimens received in the department of pathology were included in the study

\section{Exclusion criteria}

Recurrent meningioma cases and on therapy cases were excluded

\section{Sample size}

50 cases

Detailed clinical data and radiological findigs were recorded.

The tissues were routinely processed and stained with $\mathrm{H} \& \mathrm{E}$

Classified according to WHO 2016 classification

\section{WHO Grade Criteria includes}

Grade I Mitosis <4/10 hpf,

Grade II Mitosis >4-19/10 hpf (Or) 3 out of 5 histomorphological features

1. Increased cellularity

2. Patternless/sheet like growth

3. Small cells with high N/C ratio

4. Prominent nucleoli

5. Foci of spontaneous or geographic necrosis

Grade III- Mitosis > 20 /10 hpf (or)

Loss of differentiated features resulting in carcinoma,melanoma or sarcoma like appearance

Ki 67 stain was done using poly Excel HRP/DAB Detection system
Ki 67 labelling index: 1000 nuclei examined under $400 \mathrm{X}$ and results were expressed as percentage of positively stained nuclei

Interpretation of Ki 67 for Meningiomas was done based on Sanghamitra Mukherjee et al. [6] study. Mean Ki 67 labelling index of Grade I meningiomas was $1.4 \%$, Grade II meningiomas was $4.08 \%$ and Grade III meningiomas was $15 \%$.

\section{STATISTICAL ANALYSIS}

The difference in the two groups is tested for Statistical Significance using Parametric tests such as ttest and categorical variables tested by chi square test. P-value less than 0.05 considered to be statistically significant.

\section{RESULTS}

Total 50 cases of meningiomas were analysed for a period of 2 years. In the present study, majority of the patients belong to the age group of 41-60 years $(62 \%)$, followed by $21-40$ years $(28 \%)$ and $>61$ years (10\%).

In the present study, majority of the patients were females $(78 \%)$. The male: female ratio was found to be $1: 3.5$ with a clear female predominance.

In the present study, majority of the patients complained of headache alone $(34 \%)$, followed by headache with seizures (14\%), vomiting's (14\%), limb weakness $(12 \%)$, seizures $(10 \%)$, headache with vomiting's (6\%), giddiness (4\%), visual Disturbance $(4 \%)$ and altered sensorium $(2 \%)$.

Contrast imaging on CT showed hypodense lesions in $52 \%$, hyperdense lesions in $16 \%$ and isodense lesions in $12 \%$.Contrast imaging on MRI showed Isotense lesions in $10 \%$, hyperdense lesions in $6 \%$ and Hypotense lesions in 6\%. Enhancement of meningiomas showed homogenous in $98 \%$ patients and heterogenous in $2 \%$ patients.

Meningothelial Meningioma was seen in 50\% patients (Fig: 1-5), Transitional Meningioma was seen in 20\%, Fibroblastic Meningioma (Fig:6\&7), was seen in $10 \%$ patients, Psammomatous Meningioma(Fig:8), was seen in $8 \%$ patients, Atypical Meningioma was seen in $4 \%$ patients, Anaplastic Meningioma(Fig:9\&10), was seen in $2 \%$ patients, Angiomatous Meningioma was seen in $2 \%$ patients and clear cell Meningioma(Fig: 11\&12), was seen in $2 \%$ patients(Table1). Majority of the patients belongs to WHO grade $1(92 \%)$ followed by grade $2(6 \%)$ and grade $3(2 \%)$ (Table2).Ki67 index is $2 \%$ in 19 patients, $1 \%$ in 11 patients, $3 \%$ in 10 patients, $4 \%$ in 3 patients, $5 \%$ in 3 patients, $7 \%$ in 2 patients, $8 \%$ in 1 patient and $21 \%$ in 1 patient(Table 3 ). 
Table-1: Distribution of patients based on the histopathological examination $(n=50)$

\begin{tabular}{|l|l|l|}
\hline & Frequency & Percent \\
\hline Meningothelial Meningioma & 25 & $50.0 \%$ \\
\hline Transitional Meningioma & 10 & $20.0 \%$ \\
\hline Fibroblastic Meningioma & 5 & $10.0 \%$ \\
\hline Psammamatous Meningioma & 4 & $8.0 \%$ \\
\hline Atypical Meningioma & 2 & $4.0 \%$ \\
\hline Anaplastic Meningioma & 1 & $2.0 \%$ \\
\hline Angiomatous Meningioma & 1 & $2.0 \%$ \\
\hline clear cell Meningioma & 1 & $2.0 \%$ \\
\hline Microcystic Meningioma & 1 & $2.0 \%$ \\
\hline Total & 50 & $100.0 \%$ \\
\hline
\end{tabular}

Table-2: Distribution of patients based on the WHO grading. $(\mathbf{n}=\mathbf{5 0})$

\begin{tabular}{|l|l|l|}
\hline & Frequency & Percent \\
\hline Grade 1 & 46 & $92.0 \%$ \\
\hline Grade 2 & 3 & $6.0 \%$ \\
\hline Grade 3 & 1 & $2.0 \%$ \\
\hline Total & 50 & $100.0 \%$ \\
\hline
\end{tabular}

Table-3: Distribution of patients based on the WHO grading and ki67 index $(n=50)$

\begin{tabular}{|c|c|c|c|c|c|c|c|c|c|c|}
\hline & \multicolumn{7}{|c|}{ ki67index } & \multirow{2}{*}{$\begin{array}{l}\text { Tot } \\
\text { al }\end{array}$} \\
\hline & & & $1 \%$ & $2 \%$ & $3 \%$ & $4 \%$ & $5 \%$ & $7 \%$ & 21 & \\
\hline \multirow{7}{*}{$\begin{array}{l}\text { W } \\
\text { HO } \\
\text { Gra } \\
\text { de }\end{array}$} & \multirow{3}{*}{$\begin{array}{l}\mathrm{Gr} \\
\text { ade } \\
1\end{array}$} & $\mathrm{~N}$ & 11 & 20 & 10 & 3 & 3 & 0 & 0 & 47 \\
\hline & & $\%$ & 10 & 10 & 10 & 10 & 10 & $0 \%$ & $0 \%$ & 94. \\
\hline & & & $0 \%$ & $0 \%$ & $0 \%$ & $0 \%$ & $0 \%$ & & & $0 \%$ \\
\hline & \multirow{2}{*}{$\begin{array}{l}\mathrm{Gr} \\
\text { ade } \\
2\end{array}$} & $\mathrm{~N}$ & 0 & 0 & 0 & 0 & 0 & 2 & 0 & 2 \\
\hline & & $\%$ & $0 \%$ & $0 \%$ & $0 \%$ & $0 \%$ & $0 \%$ & $\begin{array}{l}10 \\
0 \%\end{array}$ & $\begin{array}{l}0.0 \\
\%\end{array}$ & $\begin{array}{l}4.0 \\
\%\end{array}$ \\
\hline & \multirow{2}{*}{$\begin{array}{l}\mathrm{Gr} \\
\text { ade } \\
3\end{array}$} & $\mathrm{~N}$ & 0 & 0 & 0 & 0 & 0 & 0 & 1 & 1 \\
\hline & & $\%$ & $0 \%$ & $0 \%$ & $0 \%$ & $0 \%$ & $0 \%$ & $0 \%$ & $\begin{array}{l}10 \\
0 \%\end{array}$ & $\begin{array}{l}2.0 \\
\%\end{array}$ \\
\hline \multirow{3}{*}{\multicolumn{2}{|c|}{ Total }} & $\mathrm{N}$ & 11 & 20 & 10 & 3 & 3 & 2 & 1 & 50 \\
\hline & & $\%$ & 10 & 10 & 10 & 10 & 10 & 10 & 10 & 100 \\
\hline & & & $0 \%$ & $0 \%$ & $0 \%$ & $0 \%$ & $0 \%$ & $0 \%$ & $0 \%$ & $\%$ \\
\hline
\end{tabular}

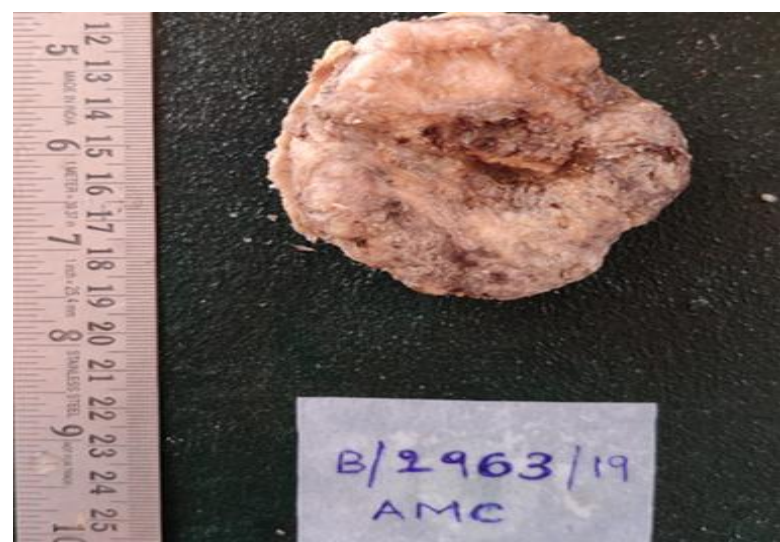

Fig-1: Photomicrograph showing gross specimen of Meningothelial meningioma measuring $5 \times 4 \times 3 \mathrm{~cm}$

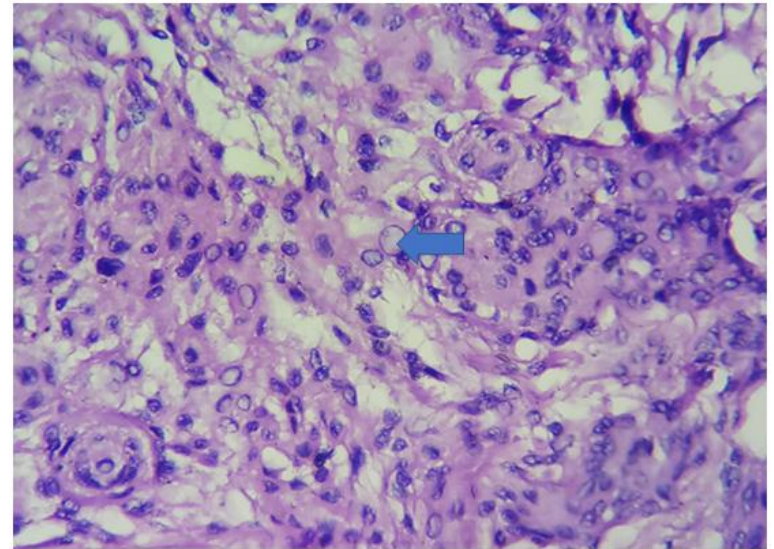

Fig-2: Photomicrograph showing pseudo nuclear inclusions of meningothelial meningioma $\mathrm{H} \& \mathrm{E}(400 \mathrm{X})$

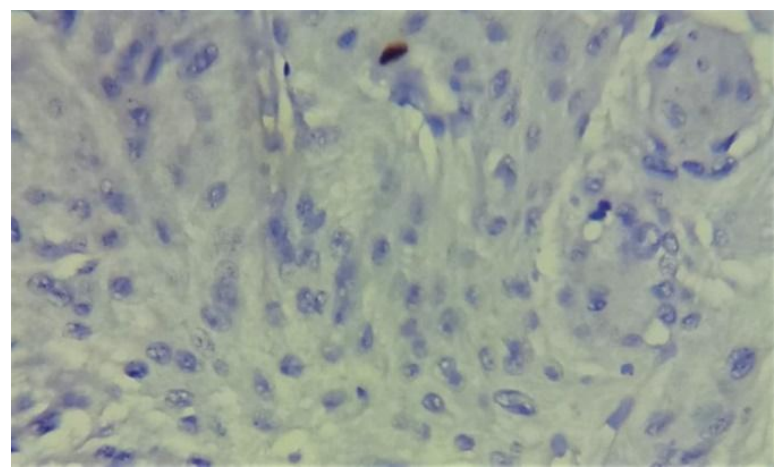

Fig-3: Photomicrograph showing Ki67 1\% positivity in Meningothelial meningioma IHC (400X)

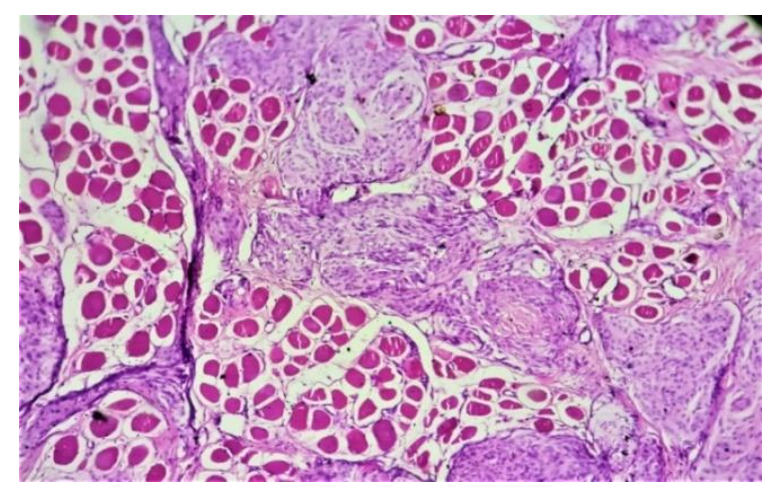

Fig-4: Photomicrograph showing temporal muscle entrapment by Meningothelial cells in meningothelial meningioma. H\&E(100X)

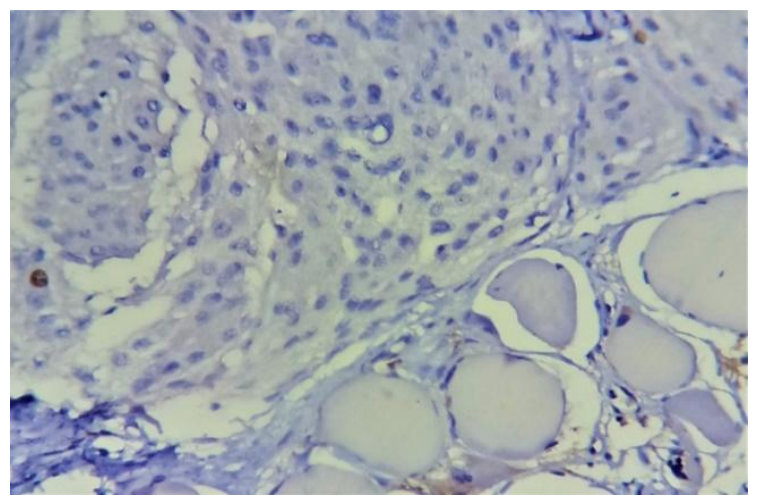

Fig-5: Photomicrograph showing Ki $671 \%$ positivity in meningothelial meningioma having temporal muscle entrapment. IHC (400X) 


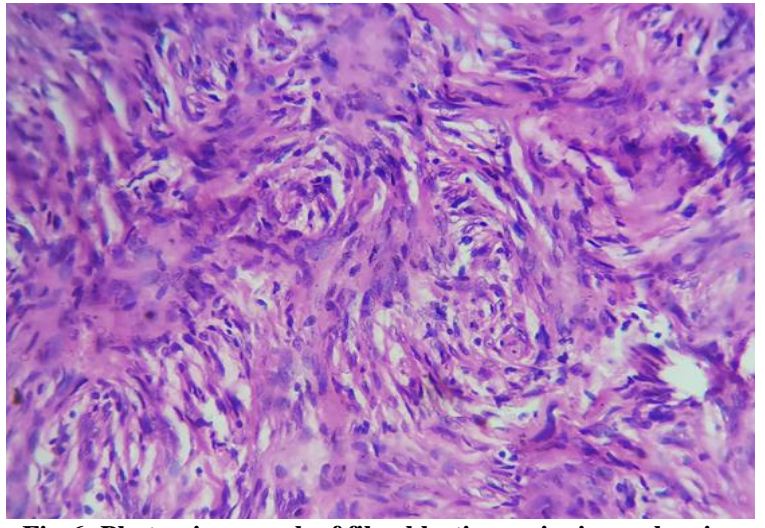

Fig-6: Photomicrograph of fibroblastic meningioma showing spindle cells arranged in fascicles and storiformpattern. H\&E(400X)

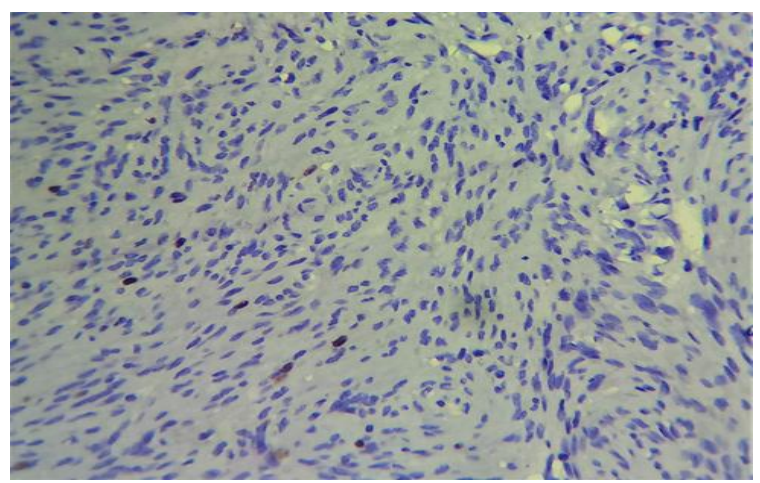

Fig-7: Photomicrograph showing Ki67 5\% positivity in fibroblastic meningioma. IHC (400X)

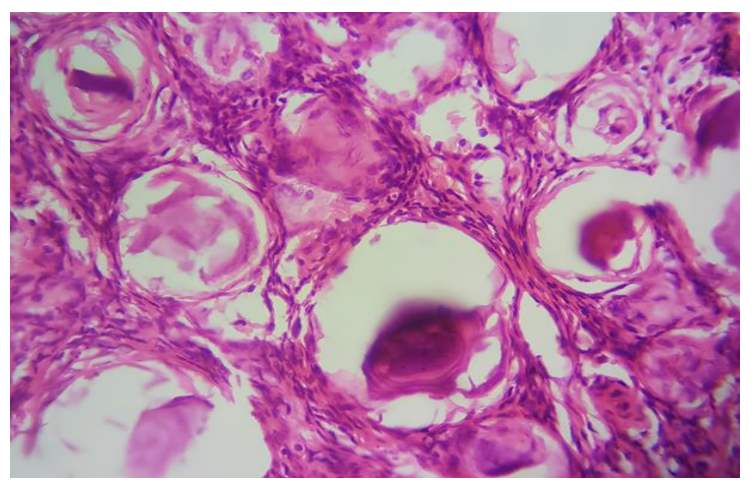

Fig-8: Photomicrograph showing concentric layers of Calcium deposits(psammoma bodies). H\&E(400X)

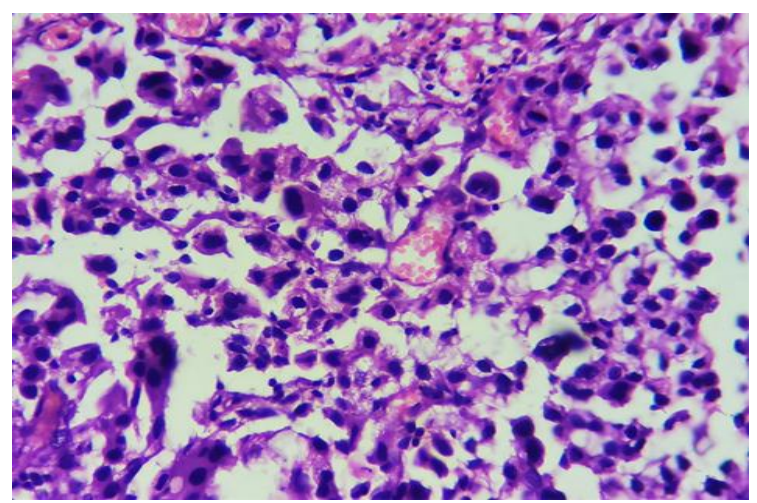

Fig-9: Photomicrograph of Anaplastic meningioma showing pleomorphic cells and mitotic figures. H\&E (400X)
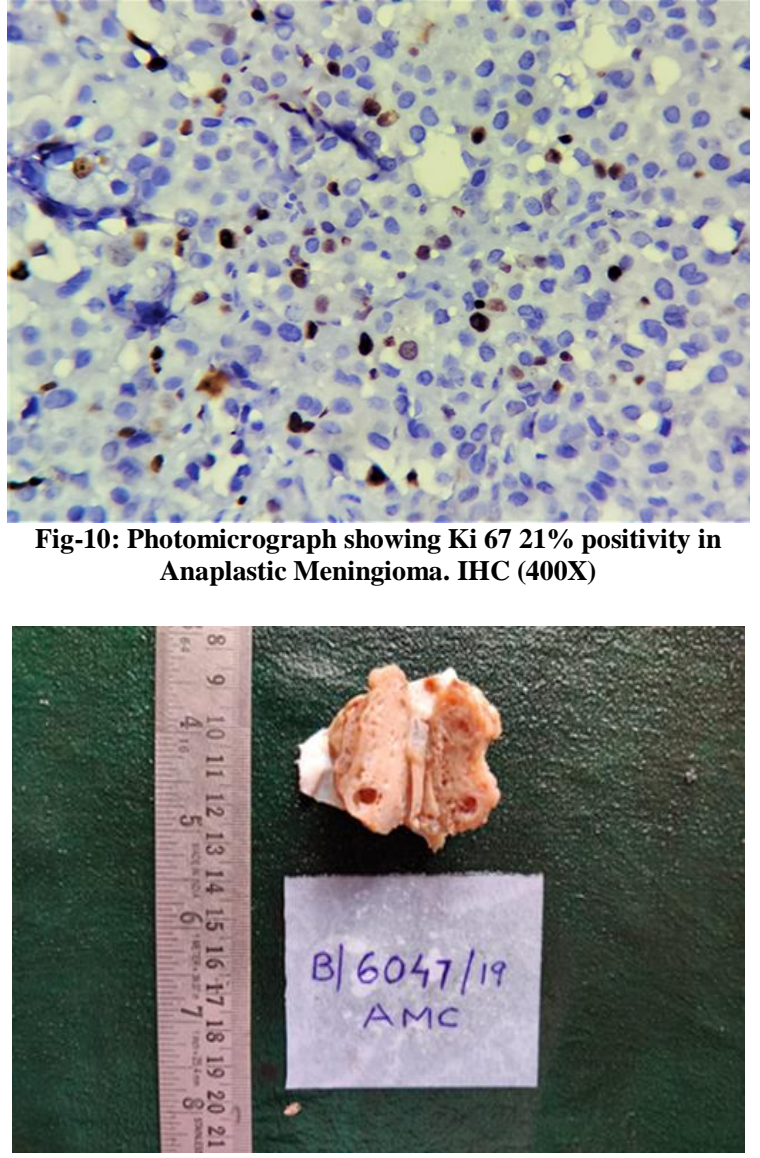

Fig-11: Photomicrograph showing cut section of clear cell Meningioma with cystic spaces and attached dural base

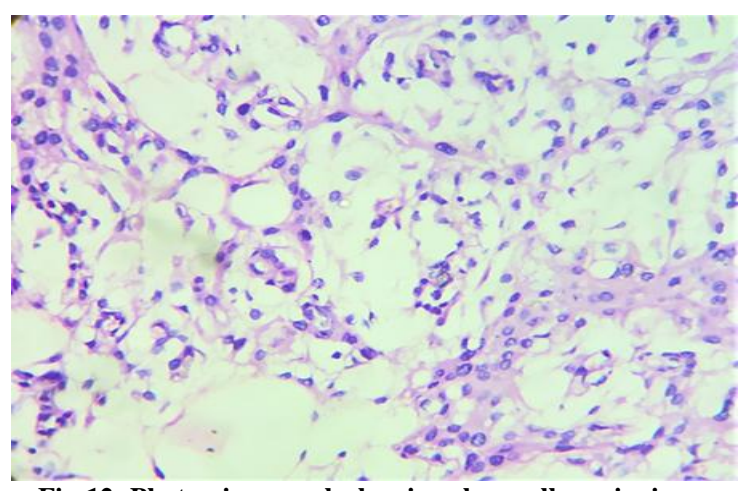

Fig-12: Photomicrograph showing clear cell meningioma exhibiting cytoplasmic clearing of cells .H\&E (400X)

\section{DISCUSSION}

In the present study, 50 cases of meningioma were studied and classified according to the latest WHO classification 2016. In the present study, 31 cases $(62 \%)$ of meningiomas were noticed in fourth to sixth decade. These results were in concordance with the study conducted by Desai et al. [7] which showed maximum incidence in the fourth and fifth decade.

Meningiomas are rare in children [8]. Our study also found similar results. In our study, we found no paediatric case. Out of the 50 cases in our study, 11 were male and 39 were female. The male: female ratio was found to be 1: 3.5 with a clear female 
predominance. Our results were comparable to those found in a study conducted by Backer et al. [9] showing male:female ratio 1:3. In our study, we found maximum number of meningioma cases in the 4th to 6th decade for both the genders. This is comparable to the studies conducted by Patil et al. [10] where maximum number of cases was seen in 4th and 5th decade in both the genders and Dhanapandian et al. [11] where maximum number of cases was seen in 4th decade in both genders.

Majority of the patients complained of headache alone (34\%), followed by headache with seizures (14). In Masoodi T et al. [12] headache was the most common symptom $(69.6 \%)$ followed by seizures $(35.9 \%)$.

Majority of meningioma cases in our study were supratentorial in location. A study conducted by Shri Lakshmi et al. noted $90 \%$ cases in supratentorial location [13].

Meningiomas are usually iso to hypointense on T1 weighted imaging [14]. In our study, Contrast imaging on MRI showed Isointense lesions in $10 \%$.

Although most of the meningiomas are benign, histologically distinct subtypes are associated with aggressiveness. Out of the total 50 meningioma cases, Majority of the patients belongs to WHO grade $1(92 \%)$ followed by grade $2(6 \%)$ and grade $3(2 \%)$. Gadgil et al. [15], in his study on meningioma noted $85.6 \%$ grade I, $11.5 \%$ grade II and $2.9 \%$ grade III. A study by Desai et al. [7] found the percentage of grade I, grade II and grade III meningiomas to be $90 \%, 8 \%$ and $2 \%$ respectively.

Meningothelial meningioma composed of 25 out of 50 cases $(50 \%)$ of meningioma. Meningothelial variant was the most common variant in Moradi et al. [16], Jindal et al. [17] and Patil et al. [10] accounting for $33.7 \%, 50 \%$ and $43.67 \%$ respectively whereas transitional variant was commonest in the studies done by Backer et al. [9].

Mean Ki 67 LI of Grade I meningiomas was $2.3 \%$, Grade II meningiomas was $7.3 \%$ and Grade III meningioma showed Ki 67 LI of $21 \%$ in present study.

In Mukherjee S et al. [6] Mean Ki 67 LI of Grade I meningiomas was $1.4 \%$, Grade II meningiomas was $4.08 \%$ and Grade III meningioma was $15 \%$. In Babu S et al. [18] Grade-I meningiomas constituted about $90 \%$, Grade-II about $7 \%$ and Grade-III about $2 \%$ of the meningiomas

Histopathologic grading is one of the important predictors of recurrence. Ki 67 LI correlates with histological grade and recurrence. However, all the tumours in each grade do not behave uniformly.

\section{CONCLUSION}

Meningiomas are the most common primary central nervous system tumour of adults with a female predilection. The major prognostic factors for recurrence include tumour grade, biological behaviour of tumour and extent of surgery. Ki 67 helps in predicting tumour behaviour. Therefore Ki 67 index can be used as an accessory tool to grading system and helps the surgeon in establishing better follow up criteria and long term management strategies for the benefit of the patient.

\section{ACKNOWLEDGEMENTS}

We thank the Multidisciplinary research unit (MRU), Government of India, Ministry of Health \& Family Welfare, New Delhi for the infrastructure provided to conduct the study.

\section{REFERENCES}

1. Louis, D.N., Ohgaki, H., Wiestier, O.D., Cavenee, W.K., Ellison, D.W., Figarella-Branger, D. (2016). WHO Classification of Tumours of the Central Nervous System. In: Hiroko DNL, Otmar DO. Webster KW editors. 4th Edition. France: International Agency for Research on Cancer.

2. Bhatti, P., Veiga, L. H., Ronckers, C. M., Sigurdson, A. J., Stovall, M., Smith, S. A., ... \& Friedman, D. L. (2010). Risk of second primary thyroid cancer after radiotherapy for a childhood cancer in a large cohort study: an update from the childhood cancer survivor study. Radiation research, 174(6a), 741-752.

3. Hijiya, N., Hudson, M. M., Lensing, S., Zacher, M., Onciu, M., Behm, F. G., ... \& Rivera, G. K. (2007). Cumulative incidence of secondary neoplasms as a first event after childhood acute lymphoblastic leukemia. Jama, 297(11), 12071215.

4. Sadetzki, S., Chetrit, A., Freedman, L., Stovall, M., Modan, B., \& Novikov, I. (2005). Long-term follow-up for brain tumor development after childhood exposure to ionizing radiation for tinea capitis. Radiation research, 163(4), 424-432.

5. Gerdes, J. (1990, June). Ki-67 and other proliferation markers useful for immunohistological diagnostic and prognostic evaluations in human malignancies. In Seminars in cancer biology (Vol. 1, No. 3, pp. 199-206).

6. Mukherjee, S., Ghosh, S. N., Chatterjee, U., \& Chatterjee, S. (2011). Detection of progesterone receptor and the correlation with Ki-67 labeling index in meningiomas. Neurology India, 59(6), 817.

7. Desai, P. B., \& Patel, D. (2016). Histopathological study of meningioma. International Journal of Medical Science and Public Health, 5(2), 327-331.

8. Baumgartner, J. E., \& Sorenson, J. M. (1996). Meningioma in the pediatric population. Journal of neuro-oncology, 29(3), 223-228. 
9. Backer-Grøndahl, T., Moen, B. H., \& Torp, S. H. (2012). The histopathological spectrum of human meningiomas. International journal of clinical and experimental pathology, 5(3), 231.

10. Patil, P., Patil, P.R., Sondankar, D.(2016). Clinicopathological Study of Meningioma. Int $\mathrm{J}$ Med Res Rev, 4(4):592-601.

11. Dhanapandian, J., Merla, J. (2016). A Study of Meningiomas in Tertiary Care Center in South India. IOSR J Dent Med Sci, 15(10):7-12.

12. Masoodi, T., Gupta, R.K., Singh, J.P., Khajuria, A. (2012). Pattern of central nervous system neoplasms: A study of 106 cases. JK Pract, 17(4):42-46.

13. Lakshmi, S.S. (2015). Meningiomas: A Clinicopathological study. Int J Med Res Heal Sci, 4(4):827-831

14. Mary, A.K., Mary, A.K., Abuya, J.M., Chumba, D., Koech, F.K.(2013). The Common Radiological
Features of Meningiomas on CT scan and MRI among Patients at Major Hospitals in Eldoret, Kenya, 2(2):213-226.

15. Gadgil, N.M., Margam, S.R., Chaudhari, C.S., Kumavat, P.V. (2016). The histopathologicalspectrum of meningeal neoplasms. Indian J Pathol Oncol, 3(3):432-436.

16. Moradi, A., Semnani, V., Djam, H. (2008). Pathodiagnostic parameters for meningioma grading. J ClinNeurosci. 15(12):1370-1375.

17. Jindal, A., Choudhary, S. (2016). A Clinicopathological Study of Meningioma with Special Reference on Variants and Grading in a Tertiary Care Centre. Int J Med Res Prof, 2(3):192196.

18. Babu, S., Uppin, S. G., Uppin, M. S., Panigrahi, M. K., Saradhi, V., Bhattacharjee, S., \& Challa, S. (2011). Meningiomas: correlation of Ki67 with histological grade. Neurology India, 59(2), 204. 